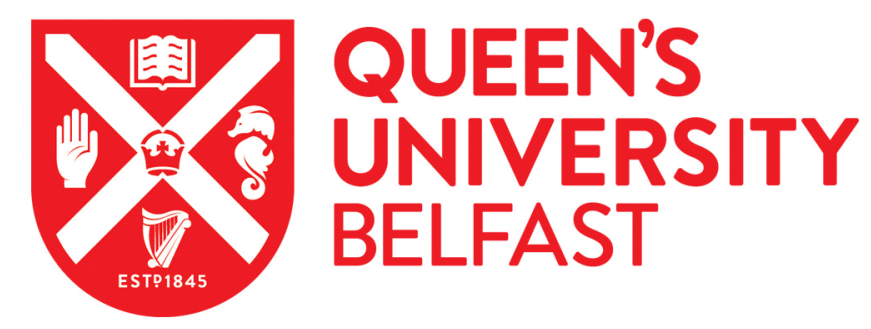

\title{
Off-Duty Resilience: Re-orienting Tourism, Leisure and Recreation in the US Army BOSS program
}

Lisle, D. (2016). Off-Duty Resilience: Re-orienting Tourism, Leisure and Recreation in the US Army BOSS program. American Quarterly, 68(3), 747-768. https://doi.org/10.1353/aq.2016.0061

Published in:

American Quarterly

Document Version:

Publisher's PDF, also known as Version of record

Queen's University Belfast - Research Portal:

Link to publication record in Queen's University Belfast Research Portal

Publisher rights

Copyright $($ The American Studies Association, The Johns Hopkins University Press. This article first appeared in American Quarterly , Volume 68, Issue 3,

September 2016, pp. 747-768.

\section{General rights}

Copyright for the publications made accessible via the Queen's University Belfast Research Portal is retained by the author(s) and / or other copyright owners and it is a condition of accessing these publications that users recognise and abide by the legal requirements associated with these rights.

Take down policy

The Research Portal is Queen's institutional repository that provides access to Queen's research output. Every effort has been made to ensure that content in the Research Portal does not infringe any person's rights, or applicable UK laws. If you discover content in the Research Portal that you believe breaches copyright or violates any law, please contact openaccess@qub.ac.uk. 


\section{PROJECT MUSE}

Off-Duty Resilience: Reorienting Tourism, Leisure, and Recreation in the US Army BOSS Program

Debbie Lisle

American Quarterly, Volume 68, Number 3, September 2016, pp. 747-768

(Article)

Published by Johns Hopkins University Press

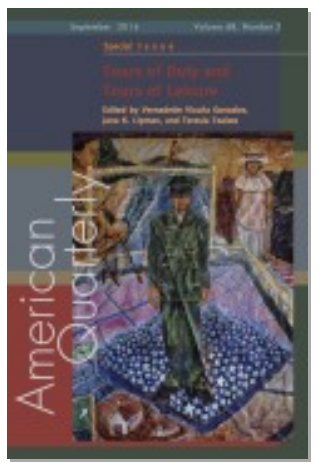

$\Rightarrow$ For additional information about this article

https://muse.jhu.edu/article/631128 


\title{
Off-Duty Resilience: Reorienting Tourism, Leisure, and Recreation in the US Army BOSS Program
}

\author{
Debbie Lisle
}

\section{Work Hard, Play Hard: BOSS and the Rebranding of Tourism, Recreation, and Leisure}

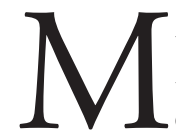

ilitary leaders have always understood that success on the battlefield requires the provision of recreation, relaxation, and leisure for activeduty soldiers. Certainly this includes moments of "down time" during tours of duty overseas (e.g., video games, fitness training, poker), but it also includes structured leave-or R\&R-where soldiers depart from the battlefield for a relaxing vacation, an adventure holiday, or more recently, a short visit home. Critical examinations of R\&R show how the off-duty time of soldiers is shaped by prevailing discourses of race, gender, class, and sexuality that are not that far removed from similar discourses operating on battlefields. ${ }^{1}$ In other words, the modes of differentiation enabling soldiers to demonize and kill enemies on the battlefield are translated through a tourist gaze enabling soldiers to exploit feminized, sexualized, and racially subservient others off the battlefield (e.g., hosts, guides, servants, cleaners, lovers, prostitutes). Indeed, the work of Cynthia Enloe clearly demonstrates that militarism, tourism, patriarchy, and racism have a long and entangled history. ${ }^{2}$ The present essay builds on those insights by critically examining how the US Army is assimilating tourism, leisure, and recreational practices within its force-wide Ready and Resilient campaign (R2), and seeks to show how this process constructs resilient soldiers against disengaged, vulnerable, abject, exotic, and servile others. The R2 campaign builds the "mental, physical, emotional, behavioral and spiritual resilience" of US Army forces to help them perform well in "environments of uncertainty and persistent danger." 3 To embed readiness and resilience across the "Total Army" (i.e., soldiers as well as their families and associated civilians), the US Army has developed comprehensive training programs to produce the "Total 
Soldier." These include increasing self-awareness and mindfulness, deterring high-risk behaviors, supporting healthy alternatives, encouraging leadership and initiative, and helping all soldiers "overcome setbacks, recover and grow from adversities and thrive on a sustained basis." ${ }^{14}$ Part of this culture shift is transforming the familiar (and often violent, sexist, and racist) logics through which US soldiers have traditionally engaged with local populations outside US bases. Indeed, R2 helps the army reshape the off-duty military tourism that had caused so much bad press in previous decades (e.g., high-profile rape cases, militarized prostitution, racially motivated violence). What interests me is how the US Army's supposedly ethical response to previous "bad behavior" (i.e., the R2 agenda) produces its own logics of asymmetry, hierarchy, and exclusion-many of which are enacted through the unexpected and often hidden practices of tourism, leisure, and recreation.

To explore the role of off-duty time in the construction of resilience, this essay focuses on the US Army's Better Opportunities for Single Soldiers (BOSS) program, which organizes officially sanctioned opportunities for tourism, leisure, and recreation both on and off military bases in the United States and abroad. The BOSS program was created in 1995 to "enhance the morale and welfare of single soldiers, increase retention and sustain combat readiness. ${ }^{\prime 5}$ It is institutionally part of the army's Family and Morale, Welfare and Recreation Programs (MWR) and organized around three platforms. The first, Quality of Life, aims to increase the well-being of all the army's soldiers. It was initially envisioned as a forum for troops to address any difficulties with their living arrangements (e.g., dilapidated barracks, broken equipment), but very quickly soldiers pushed for well-being to include personal growth and career development. As a result, BOSS's Quality of Life platform is now much more focused on cultivating leadership and providing life skills and career training across all ranks. The second BOSS platform, Community Service, includes volunteer and charity activities in local communities around Army bases worldwide. Community service has been central to the army's efforts to repair relations with local communities damaged by high-profile cases of rape, harassment, and violence, and BOSS soldiers are strongly encouraged to participate in "community programs or projects that make a difference in the lives of others, in the community and ultimately, in themselves." BOSS committees work with existing voluntary organizations such as Big Brothers and Sisters, Habitat for Humanity, and Special Olympics and participate in activities such as picking up litter, teaching fitness classes in schools, organizing recycling programs, and volunteering at soup kitchens. Not only do these charity activities help offset the cost of more recreational BOSS events, but they 
also count toward the army-wide Volunteer Recognition program (including the Outstanding Volunteer Service Medal), and most important, enhance the CVs of participating soldiers. ${ }^{7}$ Community service is a double win for the US Army because it helps meet wider efficiency targets: in the financial year 2013, BOSS volunteers accumulated 130,781 volunteer hours from over sixteen thousand volunteers that generated a "cost avoidance" of over $\$ 2.6$ million. ${ }^{8}$ The final BOSS platform, Recreation and Leisure, includes all institutionally sanctioned forms of off-base tourism, as well as recreational, sporting, and leisure activities both on-base (e.g., pool parties, talent competitions, cook-offs, $\mathrm{BBQ}$, poker nights) and off-base (e.g., paintballing, skydiving, fishing trips, concerts, ski trips). On American bases overseas (e.g., Germany, Italy, Japan, South Korea), BOSS chapters organize tourist excursions to local attractions.

There are currently sixty-nine BOSS chapters operating across the army's four areas of operation: Europe (Germany, Italy-16); Pacific (Hawai' $i$, Japan, South Korea-16); Central (California to Detroit-17) and Atlantic (Massachusetts to Florida-20). ${ }^{9}$ In 2009 the entire BOSS program was upgraded from Category "B" to Category "A," meaning it is now "considered essential in meeting organizational objectives of military services." ${ }^{10}$ BOSS is the current formation of a long-held army belief that group bonding, morale, and esprit de corps is built as much off the training ground as it is during day-to-day combat drills or "killing bad guys."11 It operates as a supportive, pastoral, and informal kind of training to make sure that all parts of a soldier's life-including leisure time, vacation time, and relaxation - are oriented toward the R2 agenda. This essay examines the asymmetrical formations of identity that currently constitute the US Army's efforts to bring tourism, leisure, and recreation practices within the parameters of R2. It is particularly concerned with the nuanced and often unexpected ways that US soldiers constitute themselves as resilient by projecting disengagement, vulnerability, abjection, passivity, servility, and exoticism onto a variety of others.

To critically examine the BOSS program, I analyzed its official history, publicity campaigns, MWR website, publicly available training materials, individual BOSS chapters, and presence on major social media sites (e.g., Facebook, Twitter). During the analysis I became particularly interested in discrepancies between how US Army officials understood BOSS to be working across all bases, how BOSS leaders on individual army bases translated and disseminated those objectives, and what soldiers enrolled in individual BOSS programs actually experienced in practice. To further support this analysis, in February 2015 I spent three days in Joint Base San Antonio, Texas_- "Military City USA" - the headquarters of the BOSS program and its "parent" organiza- 
tion, MWR. While there, I conducted extensive interviews with the head of the BOSS program as well as his superior who oversees many of the recreational facilities and programs within MWR. ${ }^{12}$ Both of them provided useful context, history, and detail on how the BOSS program operates and how it relates to the US Army's overall R2 campaign. While in San Antonio, I was also able to conduct a focus group with five soldiers involved in the San Antonio BOSS chapter (I have anonymized their contributions via the military alphabet so they are now Privates Bravo, Charlie, Kilo, Mike, and Oscar). These soldiers explained the importance of BOSS in their everyday lives, the challenges they faced trying to get colleagues to participate in "organized fun," and how BOSS was helping them articulate their own strengths, skill base, and career aspirations. It became clear in the midst of these observations, interviews, and group discussions that resilience was the most important organizing principle and guiding aspiration for both the BOSS program and MWR programs as a whole. This insight enabled me to more clearly locate the methodological framework for this essay within critical international relations (IR) scholarship that is using postcolonial, feminist, and poststructural approaches to interrogate the global reach and force of resilience. ${ }^{13}$ I see this essay very much as a starting point for further exploration not just in terms of the BOSS program itself but also how the constitutive asymmetries required to militarize a soldier's entire lifeworld —including his or her off-duty activities—are sustained and fortified by the pursuit of resilience.

\section{Ready and Resilient: The Capture of Off-Duty Time}

Since its launch in March 2013, the R2 campaign ensures that all soldiers have sixteen hours of mandatory resilience training every year. These classes focus on twelve major principles of Positive Psychology: Assertive Communication; Active Constructive Responding and Effective Praise; Activating Events, Thoughts, Consequences; Avoid Thinking Traps; Detect Icebergs; Hunt the Good Stuff; Identify Strengths in Self and Others; Mental Games; Put It In Perspective; Problem Solving; Real-Time Resilience; and Strengths in Challenges. ${ }^{14}$ What interests me is how this reorientation of mental health is designed to help soldiers cope with life off the battlefield as well as on it. In other words, building resilience is not just about ensuring on-the-job combat readiness: it is also about capturing off-duty time-including all tourism, leisure, and recreational activities arranged by BOSS — and actively reorienting it to serve the R2 agenda. This essay argues that R2's assimilation of off-duty time is actually a pernicious form of institutionalized governance that hollows 
out rather than strengthens a soldier's agency. More to the point, R2 ensures that soldiers are able to constitute themselves as resilient only if they produce subordinated others, namely, a passive and disengaged rank and file, vulnerable populations in need of help, and a silent economy of local hosts and tourist workers who serve soldiers' desires for self-improvement.

Alison Howell's recent study of how the US Army is using techniques of Positive Psychology to intervene more comprehensively in the mental health and private lives of its soldiers is a useful starting point for my critical reading of resilience. ${ }^{15}$ For the US Army, resilience has become the ultimate solution that not only improves the mental and physical fitness of soldiers (as well as their families and associated civilians) but also helps reduce the long-term health care costs for the military (as responsibility for mental and physical health is now individualized). Howell focuses specifically on the Comprehensive Soldier Fitness Program (CSF2), a form of "physical training for the mind," which extends into four other domains: "emotional, social, spiritual, and family fitness." 16 She explains how the military has become the model for how the state means to withdraw from commitments to social services, and critically examines how the military is deploying Positive Psychology to achieve that goal. What interests me about Howell's argument is the capacity of Positive Psychology to capture and order the entirety of a soldier's life: it reorients both work and leisure time around productivity and self-improvement, it frames self-reflections and relations with others around the pursuit of happiness, it reorders the past into "lessons" that preemptively install a singularly mapped future direction, and most important, it "cures" depression by capturing optimism, joy, and spontaneity. ${ }^{17}$

This essay develops Howell's insights about Positive Psychology in CSF2 to show how the incorporation of tourism, leisure, and recreation within the R2 framework completes the assimilation of a soldier's entire life into the military. For the army, resilience cannot be achieved if it is restricted to a single domain like "work" or "physical fitness"; rather, a soldier's entire lifeworld - the very way she understands herself, her position in the world, her relationships with others, and her future plans - must be reoriented toward the institutional goal of resilience. That culture shift is completed by assimilating the activities that take place in times when soldiers are supposedly not being soldiers, that is, when they are off-duty. This essay analyzes the logics of difference produced by that assimilation across all three of BOSS's platforms. Primarily, the BOSS Quality of Life platform is the most institutionally regulated because it orders how soldiers understand themselves and relate to each other within the military institution itself. Central to this platform is the identification, selection, and 
cultivation of leaders who construct themselves by producing a wider population of passive, disengaged, irresponsible, and entitled soldiers. BOSS leaders are encouraged to develop their professional skills (e.g., planning, delegation, prioritization, negotiation, reflection) by overseeing any improvements to base living conditions, organizing leisure events for troops, and acting as a "voice" for their colleagues.

While the experience of differentiating themselves from a passive rank and file bolsters the resilience of BOSS leaders, this newly acquired disposition becomes insecure when performed outside the familiar boundaries of the military and thus requires a more intense form of differentiation. This move outward, as BOSS solders engage in off-base volunteering and charity events, is what prompts the securing of resilience through a discourse of humanitarianism. All occupying militaries understand the need to rebrand their overseas adventures through a humanitarian lens, and use the appropriate rhetoric to do just that (e.g., we are not occupying, we are helping; we are not punishing, we are saving; we are not instructing, we are empowering). As many critical scholars have argued, humanitarian virtue hides constitutive asymmetries that privilege the benevolent occupiers and disempower local populations as passive, vulnerable, abject, and in need of rescue. ${ }^{18}$ In line with those critiques, I am interested in how the R2 agenda preemptively prepares US soldiers to view other populations as vulnerable and in need of assistance by constituting themselves as the virtuous, benevolent humanitarians who do the helping. This operates as an important supplement for combat preparation: on-duty training prepares soldiers to identify threats and target enemies (i.e., those who must be killed) and off-duty training prepares soldiers to identify innocent civilians in need of protection (i.e., those who must be saved).

While the first two BOSS platforms produce an idealized resilient soldier through the convergence of leadership and humanitarianism, the final BOSS platform of Recreation and Leisure encourages soldiers to turn away from the goal of helping others. Here, soldiers retreat back into the narcissistic foundations of resilience by commodifying local culture and instrumentalizing the tourism industry in ways that serve their own goals of self-improvement. Rather than help vulnerable others, soldiers utilize opportunities for off-base tourism, leisure, and recreation to refocus on themselves. For example, they become wellrounded by increasing their cultural capital through wine tasting; they become risk taking by testing their limits through skydiving; they become team players by participating in volleyball tournaments; and they become culturally sensitive by visiting the tourist attractions of host nations. This turn inward aligns with how modern subjects are increasingly understanding themselves as "projects" 
to be constantly worked on by consulting experts, learning self-reflexivity, and acquiring new experiences. ${ }^{19} \mathrm{I}$ am interested in how this narcissism subordinates local populations and tourism workers in ways that serve these highly privileged projects of selfhood. In BOSS's third platform, local populations are effaced, commodified, or reduced to the backstage role of service provider in an already fixed narrative about someone else's self-improvement.

This essay challenges the US Army's claim that by incorporating tourism, leisure, and recreation within the R2 framework, it can rid itself of the "bad behaviors" of the past-that it now does good military tourism that prevents infractions; builds resilience through learning, leisure, and play; and contributes to local economies around the world. ${ }^{20}$ The US Army may, in fact, be doing all these things, but the manner in which it thrusts its resilience training onto the world — no matter how benevolently — is not cost-free. Using the BOSS program as a case study, this essay outlines the shape of those costs for the soldiers themselves and, more important, for the tourist workers and host populations both in the United States and overseas. It is centrally concerned with how the extension of resilience training into off-duty activities is accomplished through careful and nuanced productions of otherness: leaders rather than disengaged troops, humanitarians rather than vulnerable charity cases, and self-improving visitors rather than silent servers or commodified locals. In this way, the BOSS program taps us into the complex and highly adaptive productions of difference being performed by the US Army-productions that are not entirely captured by strict logics of Imperial America / Rest of the World; colonizer/colonized; or host/guest. So while the BOSS program can be understood as extending the tradition of military tourism with all the difficulties that practice has historically produced, its capture within the R2 framework requires a much more careful institutional unpicking to reveal the invisible violence of "empowering" ideals such as leadership, humanitarianism, and self-improvement.

\section{Cultivating Leadership: Initiative, Motivation, and Reflexivity}

The first BOSS platform, Quality of Life, fulfills the R2 agenda largely by identifying leaders from within its ranks, cultivating them through targeted training opportunities, and ultimately increasing the resilience, efficiency, and strategic direction of the entire military. ${ }^{21}$ This begins with the original purpose of the Quality of Life platform where soldiers address concrete issues about their living environments. Here, soldiers learn the skills of communicating with army superiors in regular BOSS meetings and following through on multiple 
feedback and consultation mechanisms. ${ }^{22}$ For example, the US Army base in Heidelberg runs a monthly "Cheap Eats" dinner, where BOSS participants share a meal with senior leadership that allows soldiers to "speak to our chain of command and work through some issues." ${ }^{23}$ For senior officers, BOSS helps enhance feelings of belonging and purpose at all ranks: "Empowered with this responsibility, single soldiers feel more respected and bonded into the 'Army of One.' Likewise soldiers see that their voice counts and they are heard on issues that affect their well-being." ${ }^{24}$ This "360 degree feedback loop" places BOSS at the forefront of a wider organizational change within the military that is moving away from rigid hierarchies and toward more reflexive, responsive, and adaptive neoliberal management structures. Indeed, BOSS does not operate through a "top-down" imposition of specific targets on troops but instead sees itself as a responsive, adaptive, and encouraging collective that listens to its members.

Within this horizontal command structure, certain distinctions become apparent between those who are able and willing to engage with the resiliencebuilding opportunities BOSS presents, and those who are not. It claims to be open to everyone but in fact rigidly differentiates between those self-selecting "joiners" who already display leadership characteristics (e.g., motivation, confidence, initiative, assertiveness, entrepreneurialism), and those disengaged soldiers who are incapable — for whatever reason—of articulating their own circumstances, communicating their aspirations, and taking positive action to overcome challenges. At its very core, then, BOSS cultivates those soldiers who already possess the kinds of individual attributes that demonstrate resilience and relegates the rest into a rather amorphous rank and file whose chances of advancement are limited to acquiring only basic "Life Skills." Those already predisposed to joining group activities, participating in social events, and developing their career prospects will join BOSS—-some as a way to combat isolation or shyness, some to expand their social circles, and some to simply get ahead. ${ }^{25}$ Along with self-selection, potential leaders are also identified by senior officers and "Volun-Told" to become part of the BOSS management team. ${ }^{26}$ Regardless of why soldiers join, BOSS leaders constitute themselves by producing familiar inside-outside distinctions, for example, Private Kilo understands the army to be divided into three groups: those who play their video games in their rooms, those who drink excessively and go clubbing; and those like him—a self-confessed "social butterfly" — who are naturally drawn to programs like BOSS. ${ }^{27}$ Baffled by the lack of participation from rank-andfile soldiers in BOSS events— the "Negative Nancies"—Private Oscar argues that the biggest challenge for BOSS organizers is how to motivate their peers, counteract their "bored" mentality, and get them out of their rooms. ${ }^{28}$ 
This initial distinction between motivated leaders and a disengaged rank and file is further entrenched by their different training opportunities. The army takes the cultivation of self-selecting BOSS leaders very seriously through intensive leadership training for all BOSS presidents, the formalization of routine "Leader Surveys," and a new BOSS President's Incentive Program. ${ }^{29}$ Those demonstrating the highly valued ICE combination-Initiative, Creativity, and Enthusiasm — are encouraged to develop the required leadership skill set (e.g., organizing meetings, setting the agenda, identifying problems and opportunities, project planning, acquiring and managing resources, managing senior officers, and implementing change). ${ }^{30}$ We know that making the future actionable is central to the R2 agenda, which means that successful leaders have to be able to plan properly to order and bring a particular future into being. Thus, BOSS leaders are taught to use planning tools (e.g., skills identifier, shared twelve-month calendar, daily activity report, and "Meeting Minute" template) to help them "create, formalize, plan, conduct, and critique an event." ${ }^{31}$ Another aspect central to the $\mathrm{R} 2$ agenda is constant reflection and feedback, which means that BOSS leaders are expected to critique their own self-planned events by asking what worked, what did not work, and why. A central tension thus develops between, on the one hand, commander instructions of "Don't Forget to Have Fun!," and on the other hand, BOSS leaders ensuring that they are constantly "switched on" to review, reflect, and critique their activities as they happen. Certainly this reveals something significant about how properly resilient subjects must always be attentive to a forward momentum and can never experience unscheduled "time off"; indeed, BOSS leaders cannot relax when an event is over, as they must immediately engage in "reflection" and "evaluation" to make the next event even better. As the "BOSS Action Review" filled out at the end of each event states: "Every comment is feedback that can be used!" 32 These practices also reveal something important about the way that resilience mobilizes every second of every day, every space of operation (including cognitive ones), and every potential activity (including "off-duty" moments of relaxation, fun, and switching off). Here, we see how even the self-selecting BOSS leaders who supposedly display all the "right" attributes cannot escape the relentless monitoring, surveillance, and management that is central to R2's "reflexive" ethos.

What, then, of those soldiers who do not self-select into BOSS and who are not given opportunities for detailed skills acquisition and career progression? Characterizing these troops as passive, entitled, uneducated, and unskilled also makes them available to be molded, improved, and made productive through various BOSS interventions. For example, they are more subject to overt dis- 
ciplinary measures (for they make more mistakes, are unwilling to learn, and are incapable of disciplining themselves), and always on the receiving end of mentoring and counseling (for they are unable to self-direct and self-manage). In framing the rank and file of soldiers in these remedial terms, the Quality of Life component of the BOSS program has become the main vehicle for the US Army to deliver basic education and personal Life Skills_- "What Mom and Dad didn't teach them"- - like hygiene, health, nutrition, and skills identification. For the head of MWR, using BOSS in this way serves two purposes. First, BOSS activities embed resilience in everyday life in ways that enhance the mandatory sixteen hours of annual classroom resilience training. BOSS activities like paintballing and cooking classes help soldiers feel and experience how resilience is generated through play as well as work. Second, engagement with the BOSS program, especially through informal practices like personto-person mentoring, instills a basic morality in soldiers such that they can now be trusted to avoid "bad behavior" when they venture off-base. As the head of MWR explains, "We have to trust that the soldier will go out and do the right thing." 33 This moralization is now enshrined in a new "Safety" component of Life Skills provision aimed at countering drug and alcohol abuse, and reproduced by BOSS campaigns that target binge drinkers ("Don't be THAT guy") and promote awareness of sexual assault ("I AM STRONG""Intervene, Act \& Motivate"). ${ }^{34}$

While BOSS may be at the forefront of a more consultative and horizontal management style, its focus is cultivating the individualism at the heart of the R2 campaign: it is up to the individual soldier, not the institution, to get ahead. BOSS provides a way for soldiers to craft their own pathway for self-improvement by disseminating the idea that resilience is built from the inside-from each individual soldier identifying his or her own needs and priorities, locating any obstacles to his or her flourishing, and using BOSS structures to help increase his or her well-being. What interests me is how the cultivation of leadership within BOSS programs favors particular modes of individualization over others and in the process leaves behind those who do not demonstrate valued attributes such as "initiative, creativity and enthusiasm." This constitutive distinction between leaders and followers sets up an internal logic in which a passive audience must always be present: not everyone can be a leader, so a rank and file must be produced in ways that require peer leaders to improve it. While the "Negative Nancies" avoid, ignore, or contest opportunities for self-improvement, BOSS leaders become even more flexible, strategic, and creative to try and mobilize their colleagues. Indeed, those BOSS leaders demonstrating exceptional skills are selected for a "Master Resilience Training" 
course that teaches the central philosophies, competencies, and techniques of Positive Psychology to help leaders better motivate their peers. ${ }^{35}$ As Sergeant McCutchen explains:

I now have an extra tool that I can use. . . I'm still going to expect Soldiers to meet the standard, however, I now know there's a better way I can motivate them and approach them. I can teach these Soldiers deliberate breathing, give them visualization of succeeding, action words to motivate and help them with goal setting and staying focused. So many of the skills that we are taught can apply to any given situation. ${ }^{36}$

This last sentence is extremely revealing: resilience training applies at any given time - including off-duty time. BOSS's role in the assimilation and reorientation of a soldier's entire life toward the goal of resilience can be enacted only through a fundamental and constitutive distinction between, on the one hand, those leaders who embody resilience, evangelize about its benefits, and enthusiastically step up to train the rank and file on how to become resilient, and on the other hand, an objectified, passive, and entitled population that is preemptively identified as such, put under surveillance, and made available for intervention by peer leaders.

\section{Becoming Humanitarian: Feeling Good by Giving Back}

The kind of resilient leadership envisioned by the US Army is not confined to military bases; indeed, the skills acquired in BOSS's first platform must also translate into engagements with local communities. What is revealed in this turn outward is an anxiety over the whole project of resilience-whether it has actually been achieved and whether it will survive outside military culture. This presumption of fragility (e.g., "is 16 hours of mandatory resilience training enough?") opens the door for the discourse of humanitarianism to help protect newly resilient subjects as they leave the confines of the military base. The best way to confirm one's identity as a self-contained resilient subject is to explicitly demonstrate that capacity by helping others less fortunate than you. The Community Service platform of BOSS is important for the way it reveals the exhibitionist character of resilience: it must be constantly shown, performed, and demonstrated against lesser populations. BOSS therefore constructs local communities as lacking resilience, resources, and capacities-all of which can be remedied by overt demonstrations of BOSS soldiers' skills (e.g., teaching basketball), their physical capacity for labor (e.g., cleaning up litter), and their commitment to service (e.g., volunteering in soup kitchens). This exhibitionism indicates that for BOSS leaders, it is not enough to inhabit 
resilience if the results cannot be expressed, confirmed, and contrasted against lesser subjects - especially those outside the confines of the military institution.

Howell suggests that the wider "humanitarianization" of the US Army is directly linked to the retrenchment of the state, comprehensive cuts to welfare and social care, and the predictable rise of strategies like volunteerism to fill the gaps ${ }^{37}$ Here, the state devolves more and more responsibility and financial cost to the individual: those individuals who cannot cope with these new burdens, for whatever reason, become abject (and therefore targets for charity and improvement), whereas those individuals who are "resilient" enough (and have received the proper resilience training) adopt the identity of "the humanitarian" and help those who are less fortunate. Importantly, humanitarian notions of helping are "sold" through their affective charge: the powerful feelings of magnanimity, moral superiority, benevolence, and smugness that arise when one seeks to help others who are preemptively deemed less fortunate. For example, in the images of community projects in BOSS Fort Wainwright, Alaska (e.g., food drives, helping kids), the volunteers are repeatedly depicted as "cool." 38 Describing her favorite BOSS project of helping out at a soup kitchen, Staff Sergeant Peta-gaye Lakharam says: "I really like helping other people and doing something positive.... Seeing the faces of the people we were helping was just amazing. Hopefully, we helped to change their whole day." ${ }^{39}$ Likewise, Staff Sergeant Kristian A. Rubio from Torii Station in Japan describes a BOSS-organized Santa visit to a local special-needs school: "Being able to see the children's eyes light up and smiles glow was an incredible feeling. ... The children were the ones that filled my heart with Christmas Spirit." ${ }^{\prime 0}$ Because the power of that charge is both individualized and disavowed (i.e., "I'm doing it for them, not me!"), it effaces the structural asymmetries embedded in notions of humanitarianism-those logics that increase the narcissism and privilege of the helper while reducing the agency, voice, and capacity of the recipient.

Two things in particular interest me about BOSS's off-base humanitarianism. First, all recipients of BOSS charity must be constructed in advance as somehow vulnerable and in need so that BOSS leaders can provide whatever help, support, and guidance is required. This is why local schools and children's groups feature heavily in BOSS publicity campaigns as soldiers help teachers by managing science projects, cleaning and fixing run-down schools, providing additional sports training (e.g., aerobics, basketball), helping out on sports days, offering extra tutoring, and helping local children with their English. ${ }^{41}$ Other predesignated "vulnerable" populations that BOSS constructs in advance are veterans groups (e.g., "Hug a Veteran Day!"), the homeless (e.g., volunteering 
at soup kitchens), and the elderly (e.g., visiting care homes). What all these demonstrative humanitarian efforts illustrate is the central logic of resilience: it always requires a concomitant construction of vulnerability. Soldiers cannot achieve the powerful affective charge of benevolence without simultaneously producing a passive population in need of help—a process that eradicates the recipient's agency and reframes structural inequalities in ways that serve the needs, desires, and ambitions of the helper. ${ }^{42}$

Second, the complex geopolitical imaginary of the resilience + humanitarian nexus forces us to rethink the way US imperialism is territorialized around the world. The production of local communities as vulnerable translates no matter where BOSS community service projects operate; that is, the logic of helping (i.e., benevolent donor / vulnerable recipient) is mobilized in Seoul just as it is in San Francisco. There is no locality adjacent to a US Army base that is immune to BOSS's humanitarian efforts and the enormous energies they expend demonstrating benevolence, magnanimity, and charity. However, this logic of helping does translate differently in those BOSS Community Service projects operating through US bases overseas. These activities are similar to volunteering opportunities in the global South (e.g., aid work, gap years, volunteer tourism) that enable Western subjects to bolster their own skill sets, $\mathrm{CVs}$, and self-reflexivity while resuscitating problematic colonial relations. As many critical scholars have argued, it is very difficult to reveal the colonial logic of volunteering because of its centrality in a global neoliberal architecture that forces us to ignore fundamental questions about the retrenchment of the welfare state and the historical relations of empire that continue to fuel asymmetries between Western elites and those in the global South. ${ }^{43}$ For example, when discussing the role of BOSS on the US Army bases in South Korea, the head of MWR demonstrates how an embedded colonial logic is often sold through a discourse of humanitarianism:

It's true; we ingrain our culture on a lot of people. We did that in Korea by showing them a better way of life, for example, we showed them how to clean up their neighborhoods. When we started in 1995 it was the Old Korea with open sewers and everything, but now it is like New York City. Now they have amusement parks, theme parks and water parks ${ }^{14}$

Not only does this sentiment locate South Korea on a hierarchical ladder of development (i.e., "they were behind, but with our help, they are now catching up!"), but it also restricts South Koreans to a single collective future as grateful recipients of aid. 


\section{Going Outward by Turning Inward: Military Tourism, Narcissism, and Erasure}

The first two platforms of the BOSS program-Quality of Life and Community Service-deliver a preparatory construction of otherness in which soldiers constitute themselves as resilient humanitarians against either a passive population of unmotivated peers (within the military) or an abject population of charity recipients (outside the military). When these asymmetries translate across into BOSS's third platform-the off-duty practices of tourism, leisure, and recreation-a curious turn inward takes place. It is as if resilience has now been confirmed through the internal and external projections of otherness, and BOSS leaders are now free to congratulate themselves on that achievement. These affirmations take many forms, including self-indulgence (e.g., parties), self-improvement (e.g., learning new things), testing one's limits (e.g., risk taking), friendly competition (e.g., games and sports), and learning about the world (e.g., tourist excursions). In a sense, these activities signal a form of retreat: the very act of becoming a tourist or adventurer out in the world prompts soldiers to redirect their gaze inward and concentrate on self-improvement. These desires are enabled by piggybacking on the already established asymmetries between privileged guests and servile hosts that the Western tourist gaze perpetuates. Certainly Claudio Minca is right to argue that visiting tourists and local tourist workers always negotiate their encounters in creative, careful, and surprising ways, but what needs further examination is the extent to which BOSS's militarized framing encourages or precludes these resistive possibilities. ${ }^{45}$ In other words, when narcissistic soldier-tourists map their self-improvement narratives onto the wider practices of tourism, what spaces are available for locals to speak, maneuver, negotiate, and engage on their own terms?

The narcissism underscoring BOSS develops most clearly in on-base recreational activities where soldiers feel entitled to fully relax, close the door on work, and enjoy the fun, celebration, and excitement of a party (e.g., summer BBQs, costume parties, and Stanley Cup / Super Bowl events). The idea here is that the physical enclosure of the military base keeps soldiers away from the temptations of life outside (e.g., bars, strip clubs) and contains any possible bad behavior "in house." 46 Given the looming specter of previous "bad behavior" on R\&R, this physical separation pleases Army officials but makes BOSS parties somewhat unpopular with soldiers. The military-wide stipulation countering the "glorification" of alcohol (i.e., BOSS organizers cannot provide alcohol, nor can soldiers bring their own) means that the "letting go" 
at BOSS events is rather more constrained. Indeed, there is a perception that BOSS parties are "mandatory fun" because they enact a disingenuous "forced cohesion"; in other words, they are "corny." ${ }^{47}$ Whether popular or not, BOSS parties create opportunities for self-indulgence, relaxation, and celebration that fulfill a central pillar of the R2 agenda: these are valued practices of self-care that enable soldiers to "Hunt the Good Stuff" (i.e., increase positivity and optimism by focusing on what is good in one's life). ${ }^{48}$

BOSS supplements these forms of self-indulgence with opportunities for self-improvement by enrolling well-established forms of cultural and experiential tourism to help soldiers increase their symbolic cultural capital (e.g., cooking classes, wine tasting, music lessons, art appreciation, poetry nights, and theater outings). Truly resilient subjects know that the desire to learn new things transcends the world of employment; indeed, you must be constantly alert to new experiences, activities, and competencies that enable you to work on yourself as a project. In individualized tourist adventures in which soldiers test their physical limits and take risks (e.g., skydiving, zip lining, bungee jumping), self-improvement is about finding courage and overcoming fear. Individual resilience is also built through team-based sporting events that allow group bonding and competition to flourish during off-duty hours. Indeed, even the most innocuous BOSS event has an element of competition attached: who can eat the hottest meal; who can run the fastest mile; who can win the most volleyball/basketball/poker games. ${ }^{49}$ Army leaders know that "Competition builds resilience," but they also realize that this competition can be implicit (e.g., side-by-side group activities like skiing, running, and horseback riding) or explicit (e.g., team-based sporting activities like baseball, water polo, and bowling). ${ }^{50}$ What is important here is the cultivation of teamwork; as Sergeant First Class Betty Jeanniton explains: "We may not think alike, but as a team, we are able to build our vision of what resiliency means to us. . . A group effort is needed to help people cope with adversity, adapt to changes in their lives and build resilience when faced with setbacks." ${ }^{51}$

In all these activities of self-indulgence, self-improvement, and team building, soldier-tourists instrumentalize tourism workers in ways that bolster their own efforts to become more resilient. While figures like equestrian instructors, chairlift operators, skydiving instructors, and tour organizers are duly respected for imparting new skills and knowledge, they are only ever offered supporting roles in the soldier-tourist's primary narrative of resilience. In other words, this is a pre-scripted encounter in which soldier-tourists exploit the skills, knowledge, and labor of others for their own goals of self-improvement. My argument here is that the logics of power embedded in the first two BOSS platforms (i.e., 
active/passive, benevolent/abject) are intensified and amplified when they are experienced through the service logic of the tourist industry (i.e., privileged guests / servile hosts) that frames BOSS's third platform.

I am particularly interested in how these nested layers of asymmetry operate in a space like South Korea, where America's military presence calls forth an additional register of colonial history. American bases in South Korea host the largest BOSS program in the US Army and offer multiple opportunities for visiting soldiers to engage in military tourism (e.g., Han River cruise, shopping trips to Seoul, ski trips, and organized cultural visits). ${ }^{52}$ Many of these excursions enable US soldiers to learn about South Korean culture; for example, on Camp Red Cloud's BOSS tour to a folk village in Suwon, participants encounter local South Korean tourist workers dressed in traditional Hanbok clothing, living in traditional houses from the Joseon dynasty and engaging in traditional occupations such as making shoes. BOSS tourists can eat local food, see traditional Pugmul dance performances, and most important, purchase souvenirs (e.g., pottery, fans, musical instruments). As Specialist Lyka Cabigon explained, "I wanted to learn and experience Korean culture; knowing that the Folk Village preserved some of the oldest scenes in Korea, I wanted to see and learn more about it first-hand." ${ }^{53}$ There is much to be said, here, about how folk parks such as the one in Suwon trade in reduced and commodified accounts of "Ancient Korea" that efface its sophisticated modernity so that visitors can experience comforting feelings of superiority (e.g., smugness that they are from a "modern" culture; self-satisfaction that they are curious enough to learn about others) ${ }^{54}$ Because these cultural encounters are attached to colonial histories, they objectify local subjects as variously feminized, racialized, poor, deviant, exotic, inscrutable, intriguing, servile, and so forth. ${ }^{55}$ These distancing mechanisms are ideal for BOSS's narrative of self-improvement because soldier-tourists can conveniently enhance their "worldly" outlook by learning about "traditional" and "ancient" others. A similar mobilization of distance occurs in BOSS activities that ignore South Korean culture altogether by foregrounding its "natural habitat" as a necessary background for self-improvement. Excursions to an "Eco Park" for zip lines, white-water rafting on the Danyang River, bungee jumping, paintballing, hiking, and fishing are almost identical to many of the activities that take place during BOSS events in the United States. However, the construction of difference here is carefully calibrated: on the one hand, the landscape has to be rendered familiar (i.e., just like America) so that participants can concentrate on the more important tasks of individual adventure and peer competition; on the other hand, the background landscape has to be rendered unfamiliar and exotic so as to attract soldier-tourists off their 
bases. Unsurprisingly, foregrounding the difference of South Korea's natural landscape has an important colonial context: many Western explorers, travelers, and occupiers have depicted the Pacific as an Eden whose "innocent natives" are closer to the abundant and excessive nature on display. ${ }^{56}$

By reductively commodifying South Korean culture and carefully managing the "exotic" signifiers of South Korea's natural landscape, BOSS soldier-tourists reproduce powerful distancing mechanisms that make it hard for them to conceive of South Korean subjects speaking and acting on their own terms. Of course, South Korean subjects articulate their own agency all the time, but it is difficult for these assertions to penetrate the tightly woven colonial discourse that sustains BOSS military tourism overseas. These distancing mechanisms culminate at the annual BOSS "Beach Blast" event at the Yellow Sea beaches of Daecheon and Yeonpo. Every summer for three days, the US military rents out all the hotels at these resorts and ships in upward of seven hundred US soldiers from over forty US Army bases in the region. This BOSS event includes limbo contests, watermelon-eating competitions, tug-of-war, sandcastle contests, volleyball and hula-hoop competitions, but unlike other BOSS activities, this one also includes alcohol. The Beach Blast is important because it uses an extreme form of distancing to secure an idealized space for the self-fulfillment and troop bonding of BOSS soldiers. Indeed, the hedonism of the Beach Blast is permitted only if it is contained so that American soldiers are kept away from the wider South Korean population. Before the event, US Army and South Korean leaders engage in "back-door management" so that the local community leaves town for the duration of the event and the only South Koreans encountered by American soldiers are tourist workers (e.g., cleaners, servers, bartenders, souvenir sellers, entertainers, waiters, and chefs). ${ }^{57}$ Such a spatial and demographic segregation means that the military can contain the "bad behaviors" that used to dominate $R \& R$ breaks_-drinking, sex, fighting - within the enclave of the beach resort (i.e., American soldiers can drink, fight, and have sex with one another so that they do not drink, fight, or have sex with local South Koreans and prostitutes). ${ }^{58}$ This evacuation of South Koreans from their own landscape for three days each summer is then justified by the American military as a benevolent gesture intended to protect locals from the "natural" urges of BOSS soldiers (i.e., "it is for your own good as well as ours"). What the Beach Blast segregation actually reveals is a great deal of anxiety over unscripted encounters between American soldiers and local South Koreans that might trouble the agreement of Kapchi Da ("We Go Together"). ${ }^{59}$ Here, the worst caricatures of both populations - the hypermasculine, violent, sexualized soldier and the servile, feminized, exotic local—inform elite decision making 
in ways that privilege American desires on foreign soil and evacuate local South Koreans from their own homes, communities, and landscapes. The example of the Beach Blast makes two things clear: not only is "We Go Together" a highly unequal arrangement, but "going together" does not extend to off-duty forms of leisure and recreation.

\section{What Comes after Resilience? The Futures of Military Tourism}

This essay has explored how contemporary formations of tourism, leisure, and recreation in the US Army capture the off-duty time of soldiers and reorient it toward the R2 agenda. It examined how preparatory logics of difference are enacted in the first two BOSS platforms by creating resilient leaders (as opposed to a passive and disengaged rank and file) and benevolent humanitarians (as opposed to the vulnerable and abject recipients of charity). It then explored how these preparatory logics of difference translated-or indeed, did not translate-into the tourist, leisure, and recreational events organized by BOSS's third platform. These leisured activities are politically significant because they require a turning inward that breaks the link between resilience + humanitarianism established during BOSS's Well-Being and Community Service platforms. What is revealed in these practices is a foundational narcissism that saturates the entire $\mathrm{R} 2$ agenda; that is, to create a ready and resilient force, soldiers must be taught how to build their own identity, take charge of their own self-improvement, and utilize all opportunities-including time off- to become resilient. During BOSS's tourism, leisure, and recreation events, this narcissism is intensified and amplified when it is mapped onto the existing logics of power endemic in the tourism industry; in other words, when resilient/vulnerable aligns with privileged guest/servile host. The example of BOSS tourist excursions in South Korea adds an additional layer of asymmetry through a powerful colonial discourse in which American soldiers are continually distanced from local South Koreans.

While I have no doubt that many different strands of US imperial strategy continue to make themselves felt when American soldiers go on holiday in foreign lands, I am not convinced we can understand those practices fully without recognizing the labor that goes into creating entitled soldier-tourist dispositions. Soldiers do not simply encounter otherness as if in a vacuum: they are taught how to manage their relations with difference through countless forms of institutionalized training and preparation. In the context of the army-wide R2 agenda, these anticipatory productions of otherness are particularly difficult to track and make sense of-even more so when they involve mobilities like 
tourism. This essay works as an opening into that terrain: a case study of the BOSS program that brings us closer to working out - and troubling-how the US Army's efforts to create resilient forces is resuscitating, adapting, and strengthening familiar US imperial strategies.

\section{Notes}

The author would like to thank Sergeant Adam Hughes (head of the US Army BOSS program) for helping me arrange my field research, patiently answering my questions, showing me around the San Antonio installation, and being such a gracious and generous host; and Sergeant Major Michael Hatfield (head of the US Army Family, Morale, Welfare and Recreation Program) for clarifying the role of BOSS within the wider US Army framework, engaging my interest in how the US Army provides resilience training, and providing some very useful context and history. I also benefited enormously from a very helpful (and talkative!) focus group of BOSS leaders in San Antonio. For constructive comments and suggestions, I would like to thank Alison Howell in particular, as well as panelists and audience members at the International Studies Association panel "Global Health in the Military: Gender and the Redefinition of Fitness, Injury, and Disability," in New Orleans, in February 2015.

1. Debbie Lisle, Holidays in the Danger Zone: Entanglements of War and Tourism (Minneapolis: University of Minnesota Press, 2016); see also Lisle, "Consuming Danger: Reimagining War / Tourism Divide," Alternatives: Global, Local, Political 25.1 (2000): 91-116; Carolyn O’Dwyer, "Tropic Knights and Hula Belles: War and Tourism in the South Pacific," Journal of Cultural Research 8.1 (2004): 33-50; Teresia K. Teaiwa, "bikinis and other s/pacific n/oceans," in Militarized Currents: Toward a Decolonized Future in Asia and the Pacific, ed. Setsu Shigematsu and Keith L. Camacho (Minneapolis: University of Minnesota Press, 2010), 15-31; Teaiwa, "Globalizing and Gendered Forces: The Contemporary Militarization of Pacific/Oceania," in Gender and Globalization in Asia and the Pacific, ed. Kathy E. Ferguson and Monique Mironescu (Honolulu: University of Hawai'i Press, 2008), 318-32; and Vernadette Vicuña Gonzales, Securing Paradise: Tourism and Militarism in Hawai i ind the Philippines (Durham, NC: Duke University Press, 2013).

2. Cynthia Enloe, Bananas, Beaches and Bases; Making Feminist Sense of International Politics (Berkeley: University of California Press, 2014); Enloe, Maneuvers: The International Politics of Militarizing Women's Lives (Berkeley: University of California Press, 2000).

3. US Army, "Ready and Resilient," www.army.mil/readyandresilient (accessed November 30, 2015).

4. Ibid.; see also US Army, Ready and Resilient Campaign Plan, March 1, 2013, www.army.mil/e2/cl downloads/285588.pdf.

5. The launch of BOSS in 1995 came after a long and wide-ranging consultation process with single soldiers and initially targeted "young adults aged 18-25, including unaccompanied soldiers (stationed overseas) and single parents." See Sgt. Maj. Dave Abbott and Mr. John Lavender, "The History of Boss," CONUS Training Presentation, 2012, 3-5; Better Opportunities for Single Soldiers, "About Us," www.armymwr.com/recleisure/single/aboutboss.aspx (accessed July 30, 2015); and Lt. Col. Theodore C. Fox III, "The Single Soldier Dilemma," US Army War College, April 21, 1992, 1.

6. Department of the Army, Army Community Service, Army Regulation 608-1, Washington, DC, March 13, 2013, www.apd.army.mil/pdffiles/r608_1.pdf; Army OneSource, "Army Volunteer Corps Resources," www.myarmyonesource.com/FamilyProgramsandServices/Volunteering/ArmyVolunteerCorps/ArmyVolunteerCorpsResources.aspx (accessed February 2, 2015); Department of the Army Circular, DA CIR 608-04-1, 3; Better Opportunities for Single Soldiers, "About Us," www. armymwr.com/recleisure/single/aboutboss.aspx (accessed July 29, 2015); see also Kim Wheeler, "Boss Offers Community to Single Soldiers," US Army, www.army.mil/article/91651/Boss_offers_community_to_single_Soldiers/ (accessed February 10, 2015).

7. Department of the Army Circular, DA CIR 608-04-1, 5; Wheeler, "Boss Offers Community to Single Soldiers." 
8. Department of the Army_IMCOM, "BOSS 2025," CONUS Training Presentation, 2012, 15.

9. Ibid.

10. US Army, "Operations Order 10-114: Family and MWR Better Opportunities for Single Soldiers (BOSS) Program is Designated as a Category 'A' Mission Sustaining Family and MWR Program," US Army Installation Management Command, July 6, 2009, 1; Sgt. Adam Hughes, head of the US Army BOSS Program, interview by author, San Antonio, February 23, 2015.

11. Sgt. Maj. Mike Hatfield, head of the Family Morale, Welfare and Recreation Command, US Army, interview by author, San Antonio, February 23, 2015.

12. This research has been scrutinized by the independent Ethics Committee at Queen's University of Belfast.

13. David Chandler and Julian Reid, The Neoliberal Subject: Resilience, Adaptation, and Vulnerability (Lanham, MD: Rowman and Littlefield, 2015); Brad Evans and Julian Reid, Resilient Life: The Art of Living Dangerously (Cambridge: Polity, 2014); Jonathan Joseph, "Resilience as Embedded Neoliberalism: A Governmentality Approach," Resilience 1.1 (2013): 38-52; and Marc Neocleous, "Resisting Resilience," Radical Philosophy 178 (March-April 2013), www.radicalphilosophy.com/commentary/ resisting-resilience.

14. Master Resilience Training Resource Center, "Annual Skills Training Requirement for Soldiers," Comprehensive Soldier and Family Fitness, csf2.army.mil/mrtresource.html (accessed December 12, 2015).

15. Alison Howell, "Resilience, War, and Austerity: The Ethics of Military Human Enhancement and the Politics of Data," Security Dialogue 46.1 (2015): 1-17, 15-31; see also "Resilience as Enhancement: Governmentality and Political Economy beyond Responsibilisation," Politics 35.1 (2015): 67-71.

16. Howell, "Resilience, War, and Austerity," 6-7; see also Comprehensive Soldier and Family Fitness, csf2. army.mil/ (accessed November 30, 2015)

17. Howell, "Resilience, War, and Austerity," 6.

18. Chioke l'Anson and Geoffrey Pfeifer, "A Critique of Humanitarian Reason: Agency, Power, and Privilege," Journal of Global Ethics 9.1 (2013): 49-63; Mark Duffield, Global Governance and the New Wars: The Merging of Development and Security (London: Zed Books, 2001), esp. 75-107; and Makau W. Mutua, "Savages, Victims, and Saviors," Harvard International Law Journal 42.1 (2001): 201-45.

19. Nicolas Rose, Inventing Ourselves: Psychology, Power, and Personhood (Cambridge: Cambridge University Press, 1998), esp. 157.

20. Sgt. Maj. Hatfield, interview by author, February 23, 2015.

21. Abbott and Lavender, "History of Boss," 4; see also Better Opportunities for Single Soldiers, "About Us," www.armymwr.com/recleisure/single/aboutboss.aspx (accessed July 29, 2015).

22. Department of the Army Circular, Better Opportunities for Single Soldiers Program, DA CIR 608-04-1 (Washington, DC: Department of the Army, 2004), 1-7.

23. Ray Johnson, "BOSS Program Leaders in Europe Attend Training Session," US Army, www.army.mil/ article/20940/boss-program-leaders-in-europe-attend-training-session/ (accessed July 28, 2015).

24. Army Study Guide, "About Better Opportunities for Single Soldiers," www.armystudyguide.com/ content/army_board_study_guide_topics/army_programs/about-better-opportunitie.shtml (accessed July 30, 2015).

25. BOSS Focus Group Discussion, San Antonio, February 23, 2015.

26. Pvt. Mike, BOSS Focus Group, February 23, 2015.

27. Pvt. Kilo, BOSS Focus Group, February 23, 2015.

28. Pvt. Oscar, BOSS Focus Group, February 23, 2015. There is much to be studied here about how the leader-follower distinction maps onto familiar logics of gender, race, and class. My initial analysis suggests that BOSS goes to great lengths to ensure the racial and gendered diversity of its leadership (which is apparent in all its publicity images) but that class markers may predetermine who self-selects into BOSS.

29. Department of the Army-IMCOM, "BOSS 2025," 6, 14; Paul Rohler, BOSS President's Incentive Program, www.armymwr.com/UserFiles/file/BOSS/BOSS_IncentiveProgram.pdf (accessed February 9, 2015).

30. Department of the Army Circular, DA CIR 608-04-1, 7 .

31. Brian Chambers, Michelle McQueery, and Sgt. Adam Hughes, "Event Planning," CONUS Training Presentation, 2012, 2; Department of the Army-IMCOM, "Meeting Minute Tool; Supplemental Funding Request Tool, Event Publisher Tool," 2012, 1-4; Department of the Army-IMCOM, "BOSS 2025," 14. 
32. Chambers, McQueery, and Hughes, "Event Planning," 7.

33. Sgt. Maj. Hatfield, interview by author, February 23, 2015, San Antonio, TX.

34. Department of the Army_-IMCOM, "BOSS 2025," 9; Camp Darby BOSS program, www.army.mil/ article/28357/Camp_Darby_Better_Opportunities_for_Single_Soldiers_dominated_by_Air_Force/ (accessed July 27, 2015).

35. US Army, Military Resilience Training: Program Modules, www.gordon.army.mil/acs/Deployment/ MILITARY\%20RESILIENCE\%20TRAINING\%20_MRT_\%20CATALOG.pdf (accessed December 1, 2015); see also Master Resilience Training Resource Centre, csf2.army.mil/mrtresource.html (accessed December 1, 2015).

36. Marti Yoshida, "Master Resilience Preps Leaders for Success," US Army Training Doctrine and Command, May 1, 2015, www.tradocnews.org/master-resilience-training-preps-leaders-for-success/.

37. Howell, "Resilience, War, and Austerity."

38. Fort Wainwright BOSS's Facebook page, www.facebook.com/FortWainwrightBOSS/timeline?ref=page_ internal (accessed February 10, 2015).

39. Kari Hawkins, "Making a Difference with Soldiers and in Community," Redstone Rocket, August 13, 2014, www.theredstonerocket.com/news/article_10f0044a-22ee-11e4-9966-001a4bcf887a.html.

40. Rick Rzepka, "Soldiers Escort Santa to Special Needs School," US Army www.army.mil/article/140444/ Soldiers_Escort_Santa_to_Special_Needs_School/ (accessed February 10, 2015).

41. See, e.g., Ina Stiewitz, "Twenty Years of BOSS: Heidelberg Troops Celebrate with Community Service," US Army, www.army.mil/article/29065/20_years_of_BOSS_Heidelberg_troops_celebrate_with_ community_service/ (accessed February 10, 2015).

42. There are important questions here about how the US Army is entering into more public-private partnerships with civilian companies, and the way this process of outsourcing recasts military-civilian relations more generally. It is likely that as military and civilian infrastructures become more enmeshed, BOSS constructions of local populations as vulnerable will be challenged.

43. Nichole Georgeou, Neoliberalism, Development, and Aid Volunteering (London: Routledge, 2012); Wanda Vrasti, Volunteer Tourism in the Global South: Giving Back in Neoliberal Times (London: Routledge, 2012); and Vrasti and Jean Michel Montsion, "No Good Deed Goes Unrewarded: The Values/ Virtues of Transnational Volunteerism in Neoliberal Capital," Global Society 28.3 (2014): 336-55.

44. Hatfield, interview.

45. Claudio Minca, "The Island: Work, Tourism, and the Biopolitical," Tourist Studies 9.2 (2009): 88-108.

46. Hatfield, interview.

47. Pvt. Kilo, BOSS Focus Group, February 23, 2015.

48. "Hunt the Good Stuff" relies heavily on Positive Psychology techniques and is one of the central pillars of US Army resilience training; see Tom Blakely, "Hunt the Good Stuff' to Bolster Resiliency," Herald Union, September 24, 2014, www.herald-union.com/hunt-the-good-stuff-to-bolster-resiliency/; and Lindsey R. Monger, "Hunting the Good Stuff during Resiliency Training," US Army, December 31, 2014, www.army.mil/article/140671/Hunting_the_good_stuff_during_resiliency_training/.

49. All BOSS documentation stresses its commitment to gender equality (e.g., all images represent gender balance), and the type of activities they organize range from the more "feminine" cooking and art appreciation to the more "masculine" rock climbing and football. However, much more work needs to be done on gendered readings of BOSS, including whether women find BOSS a more "natural" home for their organizational skills, whether men feel "feminized" by joining, and whether women and men negotiate the competitive activities differently; see, as a starting point, Aaron Belkin, Bring Me Men! Military Masculinity and the Benign Façade of American Empire, 1898-2001 (Oxford: Oxford University Press, 2012).

50. Hatfield, interview. Most of these activities take place off-base in established tourist industries, but some BOSS chapters take advantage of the military-owned leisure infrastructures (e.g., bowling alleys, fishing lakes, ski hills); Hughes, interview; Hatfield, interview.

51. Capt. Antonia Greene-Edwards, "174th Inf. Bde. Builds Resilience as a Team," Air Force Print News Today, November 21, 2013, www.jointbasemdl.af.mil/news/story_print.asp?id=123371723; see also Lt. Gen. Donald M. Campbell Jr., US Army Europe Commanding General, "Teamwork Makes for a Ready and Resilient Force," US Army, October 16, 2013, www.army.mil/article/113202/Teamwork_makes_for_a_Ready_and_Resilient_force/.

52. South Korea has the largest BOSS program in the US Army; Hughes, interview; Hatfield, interview. 
53. USAG Red Cloud—Casey and Area 1 Family and MWR Magazine, In the Zone, September 2014, 23-27, www.slideshare.net/usagredcloud/in-the-zone-september-2014.

54. Stephen F. Mills, "Open Air Museums and the Tourist Gaze," in Visual Culture and Tourism, ed. David Crouch and Nina Lübbren (London: Bloomsbury, 2003).

55. For an account of how these existing discourses operate in Okinawa, see Ayano Ginoza, "The American Village in Okinawa: Redefining Security in a 'Militourist' Landscape," Journal of Social Science: International Christian University 60 (2007): 135-55, //ci.nii.ac.jp/naid/110007001166/.

56. Sujit Sivasundaram, Nature and the Godly Empire: Science and Evangelical Mission in the Pacific, 1795-1850 (Cambridge: Cambridge University Press, 2005); Rob Wilson, Reimagining the American Pacific: From South Pacific to Bamboo Ridge and Beyond (Durham, NC: Duke University Press, 2000).

57. The existing arrangement is that South Korean tourists occupy the beaches for "their" annual Mudfest party two weeks before, and then they leave (along with a majority of the local population) while American soldiers occupy the beaches for their "private" BOSS Beach Blast. This segregation is enforced through BOSS financial incentives: the Beach Blast is much cheaper for soldiers to attend than Mudfest (i.e., $\$ 160$ as opposed to $\$ 500$ ) (Sgt. Adam Hughes, telephone interview by author, January 29, 2016; and interview, February 23, 2015); for footage of the Beach Blast, including South Korean singers and dancers entertaining American troops on the beach, see 2014 BOSS Beach Blast_-Yeonpo Beach, South Korea, www.youtube.com/watch?v=VO3dcGCIhNc (accessed February 3, 2016).

58. Prostitution is still present during the Beach Blast, but it has become much less visible since the recent 2014 Army policy banning prostitution in South Korea; see General Curtis M. Scaparrotti, United States Forces Korea (USFK) Command Policy Letter No. 12, Combating Prostitution and Trafficking in Persons, October, 15, 2014; Hughes, telephone interview.

59. US Department of Defense, "Admiral Locklear, General Thurman on Republic of Korea-U.S. Ties," United States of America Embassy, October 1, 2013, iipdigital.usembassy.gov/st/english/texttrans/2013/10/20131002283932.html\#axzz3zI2OQ7e1. 